\title{
Baseline Assessment of Water, Sanitation, and Hygiene (WaSH) Infrastructure and Practices in Government Schools of the Trapeang Chour Commune, Cambodia
}

\author{
Tavia Mirassou-Wolf ${ }^{1,2}$, Ven Chanthou ${ }^{2}$, Kari Grady-Grossman², Maureen DeCoursey², and Elizabeth \\ P. Ryan ${ }^{1 *}$
}

${ }^{1}$ Department of Environmental and Radiological Health Sciences, Colorado State University, Colorado School of Public Health, Fort Collins, Colorado, USA

${ }^{2}$ Sustainable Schools International Cambodia, 2102 Kalmia Circle, Boulder, CO, USA

*Corresponding author: Elizabeth P. Ryan, Department of Environmental and Radiological Health Sciences, Colorado State University, Colorado School of Public Health, Fort Collins, Colorado 80523, USA, Tel: +1-970-491-1536;

E-mail: E.P.Ryan@colostate.edu

\begin{abstract}
Equitable access to clean water and sanitation is a sustainable development goal that merits attention in Cambodia. The purpose of this study was to examine the WaSH infrastructure, practices, and previous interventions in 8 rural government schools serving approximately 2,500 students in the Trapeang Chour Commune, Cambodia. A rapid assessment methodology was utilized to collect field data including key informant interviews with school administrators, site visits and observational surveys at local schools, and focus group interviews with parents. Observational data collection focused on existing water supply and storage infrastructure, latrine cleanliness and infrastructure, accessibility to drinking water, and other WaSH related physical resources. In addition, a rapid field test for Escherichia coli (E. coli) was carried out to determine availability to safe drinking water at each school. At the time of this assessment, seven of the eight schools had an untreated water source and at least one functioning latrine. No schools provided treated drinking water to students. The primary water source at three out of eight schools tested positive for $E$. coli. These baseline data suggest the need for sustainable WaSH program interventions and basic water infrastructure in the eight government schools of the Trapeang Chour Commune, Cambodia.
\end{abstract}

Abbreviations: CSPH: Colorado School of Public Health; CSU: Colorado State University; SDG: Sustainable Development Goals; SSI: Sustainable Schools International; SWaSH: School Water, Sanitation, and Hygiene; UN: United Nations; UNICEF: United Nations Children's Emergency Fund; WaSH: Water, Sanitation, and Hygiene
Received date: October 19, 2016

Accepted date: March 6, 2017

Published date: March 10, 2017

Citation: Ryan, E.P., et al. Baseline Assessment of Water, Sanitation, and Hygiene (WaSH) Infrastructure and Practices in Government Schools of the Trapeang Chour Commune, Cambodia. (2017) J Environ Health Sci 3(1): $1-8$.

DOI: $10.15436 / 2378-6841.17 .1168$

Keywords: Water; Sanitation; Hygiene; WaSH; SWaSH; School(s); Cambodia; Drinking water quality

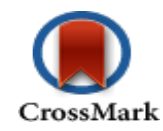

\section{Introduction}

By 2030, the United Nations (UN) aims to achieve global equitable access to clean water and sanitation as stated by the sustainable development goal (SDG) number six (WHO \& UNICEF; 2014). Cambodia has made strides to increase access to improved drinking water sources and sanitation facilities. However, these efforts have often failed, particularly in rural areas, due to lack of sustainability. Concerted efforts must be drastically accelerated to reach this goal throughout rural sectors by 2030 .

Cambodia suffers from the lowest rates of access to improved water and sanitation in Southeast Asia, with marked disparities between rural and urban areas (ISF-UTS; 2011). Inequitable access to water, sanitation, and hygiene (WaSH) negatively affects health outcomes with associations in increased rates of diarrheal disease and school absenteeism (Mara, et al., 2010; Greene, et al., 2012; Jasper, et al., 2012; Jordanova, et al., 2015). The United Nations Children's Emergency Fund (UNICEF) reports rates of improved sanitation facilities in Cambodia at $82 \%$

Copyrights: C 2017 Ryan, E.P. This is an Open access article distributed under the terms of Creative Commons Attribution 4.0 International License. 
in urban regions compared to $25 \%$ in rural regions, as well as access to improved drinking water sources as $94 \%$ in urban areas as compared to $66 \%$ in rural regions of Cambodia (UNICEF; 2015). The lack of improved sanitation facilities in rural regions promotes a practice of open defecation that spreads environmental pathogens and poses several public health concerns (Spears, et al., 2013; Rah, et al., 2015). Similarly, insufficient access to clean drinking water contributes to increased childhood diarrheal disease. Childhood diarrheal disease is the second leading cause of childhood mortality worldwide and is linked to several days of missed school each year globally (Jasper, et al., 2012; WHO, 2013; Hunter, et al., 2014; Jordanova, et al., 2015).

Emerging evidence supports the linkage between increased childhood wellness and school water, sanitation and hygiene (SWaSH) programming (Jasper, et al., 2012; Saboori, et al., 2013; Hunter, et al., 2014; Jordanova, et al., 2015; Mbuya, et al., 2016). SWaSH programming provides equitable access to WaSH resources such as sanitation facilities, improved drinking water, hand washing stations and hand soap. The provision of these resources has been associated with decreased diarrheal disease and student absenteeism from school. Furthermore, sufficient SWaSH programming and resources may naturally empower children to incite healthy behaviors within their family and community (Greene, et al., 2012; Freeman, et al., 2012). While clear evidence exists supporting these linkages, repeated failures for $\mathrm{SWaSH}$ interventions suggest an inherent complexity to this topic, even in a limited regional scope such as one community.

Prior to this study, there was no evidence for formal SWaSH programs with monitoring and evaluation in Trapeang Chour Commune, Cambodia. At the request of a local education-focused NGO called Sustainable Schools International, the research team conducted a baseline assessment to inform future programming by government, non-government and community stakeholders. The rapid assessment examined current SWaSH infrastructure, practices, and perceptions at eight government-run schools to better understand the apparent disparities and measure water quality.

\section{Materials and Methods}

\section{Setting and Demographics}

The Colorado State University (CSU) Research Integrity \& Compliance Review Office approved all study materials and procedures prior to starting this project (Protocol \#16-6365). The research was conducted in the Trapeang Chour Commune of the Aoral District in the Kampong Speu Province of Cambodia. The Trapeang Chour Commune is considered one of the more rural and remote communes in this province.

The Kampong Speu Province is 7,017 square kilometers, divided into 8 districts, and located west of the country's capital, Phnom Penh (Centre JSBaS, 2013). The Aoral District, located in northern Kampong Speu, is one of the least populated and most remote districts in Kampong Speu with a population of 29,000 (Centre JSBaS, 2013). There are five communes in the Aoral district, including the Trapeang Chour Commune with a population of approximately 10,700 (Trapeang Chour Census data 2008, 2016). The Trapeang Chour Commune was chosen for this baseline SWaSH assessment based on a partnership between CSU and Sustainable Schools International (SSI). SSI has been working to improve educational outcomes in this region since 2006. SSI's continued involvement and focus in this commune and its schools resulted in trusted relationships with key stakeholders, and enabled this team of researchers to effectively conduct this assessment.

Trapeang Chour is highly representative of rural communities in Cambodia. Formerly a forest-based economy in one of the last outposts of the Khmer Rouge, the area experienced considerable deforestation in the early 1990s and an influx of migrants from other parts of the country, a process that continues to this day. Most of the countryside has been converted to largescale industrial farms or factories where local residents work at low-paying jobs. There is no electricity and schools are poorly resourced. Girls were observed to have a high drop-out rate, especially between grades $8-9$. Before SSI began its work there in 2001, there were no school buildings and the highest level of education was Grade 6. While incomes, school infrastructure and attendance have increased over the last decade (there are now 8 official schools in the commune), most are still poorly resourced.

The study team surveyed all eight governmental schools in the Trapeang Chour Commune. Seven schools were primary schools and one was a lower secondary school. Primary school begins with a pre-school level or grade one and continues through grade six. Lower secondary school starts at grade seven and continues through grade nine. All primary schools in this study feed into the selected lower secondary school. The age of students in each grade varied based on attendance and test achievement. Table A1 provides a detailed profile of each school based on information collected at time of the SWaSH assessment.

\section{Materials}

The materials used included SWaSH surveys conducted through structured key informant interviews (KII), observational surveys, and rapid Escherichia coli (E. coli) water test kits (Aquagenx, North Carolina). The SWaSH school director questionnaires and observational surveys were provided in English and Khmer, the local language, in kind by Ray Cantwell with the non-profit Samaritan's Purse (Phnom Penh, Cambodia), a local organization who specializes in WaSH (Shantz, et al. 2014). The conduct of this assessment in person provided an opportunity to clarify questions and the observational survey allowed researchers to confirm SWaSH facility conditions and presence of resources, while minimizing response bias. This assessment was previously utilized in Cambodia by Samaritan's Purse and Clear Cambodia, and was originally developed from a survey tool produced at Emory's Rollins School of Public Health (Atlanta, GA) (Freeman, et al., 2010). The majority of survey questions $(129 / 141,91.1 \%)$ were directly applied from this SWaSH assessment tool. Additional questions were adapted from a community readiness assessment examining childhood diarrheal disease $(6 / 141,4.5 \%)$ or generated by SSI. The SWaSH questionnaire investigated: (1) school demographics, (2) knowledge \& perceptions, (3) school management and finances, (4) accountability, (5) technical information, (6) supply chain, (7) community, and (8) student engagement. Visual observation surveys explored; (1) displayed duty rosters and WaSH promotion messaging, (2) drinking water availability, (3) hand washing facilities, and (4) latrine condition. 


\section{Participants}

Based on availability, school principals, vice principals and/or teachers were recruited to answer the SWaSH questionnaires via structured key informant interviews. All but two SWaSH questionnaires were conducted in one sitting with the same key informant(s). The two questionnaires conducted in two separate interviews were necessary due to time constraints. In these two cases, the first half of the questionnaire was completed by the vice principal and the principal completed the second half of the questionnaire. A total of 10 key informant interviews were conducted. Five interviews were completed with principals, three interviews were completed by vice principals, and teachers completed two interviews (Table A1).

Table A1: Baseline School WaSH Assessment in the Trapeang Chour Commune, Cambodia.

\begin{tabular}{|c|c|c|c|c|c|c|c|c|c|}
\hline Schools & $\begin{array}{l}\text { Key } \\
\text { Informants } \\
(\mathbf{P}, \mathbf{V P}, \mathbf{T})\end{array}$ & $\begin{array}{l}\text { Grade } \\
\text { Levels }\end{array}$ & $\begin{array}{l}\text { \# of } \\
\text { students }\end{array}$ & $\begin{array}{l}\text { \# of } \\
\text { teachers }\end{array}$ & $\begin{array}{l}\text { \# of } \\
\text { Classrooms }\end{array}$ & $\begin{array}{l}\text { Distance } \\
\text { from main } \\
\text { road }\end{array}$ & $\begin{array}{l}\text { School WaSH } \\
\text { education efforts } \\
\text { in the past year }\end{array}$ & $\begin{array}{l}\text { Student/ } \\
\text { latrine } \\
\text { ratio }\end{array}$ & $\begin{array}{l}\text { Student/ } \\
\text { Functioning } \\
\text { latrine ratio }\end{array}$ \\
\hline $1^{\mathrm{a}}$ & $\mathrm{P}, \mathrm{VP}$ & Preschool- 6 & 480 & 9 & 12 & $300 \mathrm{~m}$ & Yes & $120: 1$ & $120: 1$ \\
\hline $2^{\mathrm{a}}$ & VP & $1-6$ & 141 & 4 & 4 & $4 \mathrm{Km}$ & Yes & $71: 1$ & $140: 1$ \\
\hline $3^{a}$ & VP & Preschool- 6 & 472 & 7 & 12 & $0 \mathrm{~m}$ & Yes & $118: 1$ & $236: 1$ \\
\hline $4^{\mathrm{a}}$ & $\mathrm{P}$ & $1-6$ & 230 & 3 & 3 & $20 \mathrm{~km}$ & No & $115: 1$ & $230: 1$ \\
\hline $5^{\mathrm{a}}$ & $\mathrm{P}$ & $1-6$ & 101 & 3 & 3 & $200 \mathrm{~m}$ & Yes & $34: 1$ & $101: 0$ \\
\hline $6^{a}$ & $\mathrm{~T}$ & $1-6$ & 307 & 4 & 5 & $0 \mathrm{~m}$ & Yes & $154: 1$ & $154: 1$ \\
\hline $7^{\mathrm{a}}$ & $\mathrm{P}$ & $1-6$ & 399 & 7 & 10 & $5 \mathrm{~km}$ & Yes & $100: 1$ & $133: 1$ \\
\hline $8^{b}$ & $\mathrm{P}, \mathrm{T}$ & $7-9$ & 361 & 13 & 4 & $300 \mathrm{~m}$ & Yes & $90: 1$ & $90: 1$ \\
\hline Total 8 & & & 2,491 & 50 & 53 & & & & \\
\hline
\end{tabular}

All surveys were conducted March, 2016

${ }^{\text {a }}$ Primary School; ${ }^{\mathrm{b}}$ Secondary School; $\mathrm{P}=$ Principal, VP $=$ Vice Principal, $\mathrm{T}=$ Teacher

\section{Survey procedure}

The primary researcher was from the Colorado School of Public Health (CSPH) at CSU and the secondary researcher was a local Cambodian nursing graduate from the Trapeang Chour Commune. An interpreter who was a native Khmer-speaking Cambodian with WaSH experience was also employed for this research. All stakeholder key informant interviews (KII) were conducted in person. The primary researcher read the informed consent in English and the interpreter interpreted the information into Khmer. All participants were informed that their participation in this research was voluntary and they could withdraw at any time with no penalties. All participants gave consent to participate in the study. After informed consent was granted, the secondary researcher proceeded by asking survey questions in Khmer. The majority of answers were given in Khmer and interpreted into English. The primary researcher asked clarifying questions in English to ensure proper information was gathered. Following the KIIs, both researchers completed the observational surveys by visually examining the school grounds. If resources could not be located, researchers inquired about the presence and location of the said resource. Though rare, if discrepancies in data collection occurred, the researchers discussed them at length and came to a common agreement. Given that discrepancies could have occurred due to the language interpretations, both researchers and the translator discussed reported information to ensure accurate data were recorded in each.

\section{E.coli water test procedure}

Researchers collected one $100 \mathrm{ml}$ of water, at each of the eight schools, in a sterile plastic collection pouch on the same day as the SWaSH survey and visual observations. All water samples were placed in a zip lock bag and transported back to the researchers' lodging. Rapid E.coli water tests were conducted per manufacturer's instructions (Aquagenx, North Carolina). Incubation began within 2 hours of water collection.
No electronic incubator was available on site; therefore, E. coli tests were incubated at the exterior temperature, an average of approximately $35^{\circ} \mathrm{C}$. The exterior temperature did not fall below $25^{\circ} \mathrm{C}$ at night as these tests were conducted in the hot, dry season. Test results were analyzed and recorded at 24 hours and at 48 hours after the incubation start time to ensure accurate reporting of results. Results of these tests were compared with the Most Probable Number Table (MPN)/100 ml, based on the World Health Organization Guidelines for Drinking water. These numbers were then classified into 6 health risk categories that represent the E.coli levels, ranges are as followed: low risk/ safe (i.e. $0 \mathrm{MPN} / 100 \mathrm{ml}$ ), intermediate risk/probably safe (i.e. 1 - 3.7 MPN/100ml), intermediate risk/possibly safe (i.e. 3.1 - 9.6 $\mathrm{MPN} / 100 \mathrm{ml}$ ), intermediate risk/possibly unsafe (i.e. 13.6 - 17.1 $\mathrm{MPN} / 100 \mathrm{ml}$ ), high risk/unsafe (i.e. 32.6 - $48.3 \mathrm{MPN} / 100 \mathrm{ml}$ ), and very high risk/unsafe (i.e. $>100 \mathrm{MPN} / 100 \mathrm{ml}$.

\section{Data analysis}

All key informant interviews were recorded for data analysis and clarification purposes and all responses were recorded on paper copies of the SWaSH questionnaire and visual observational survey. After each research day all data were transferred to an excel document on a locked computer. To identify common themes and existing disparities, survey data were analyzed using a content analysis approach.

\section{Results}

\section{Water access \& drinking water}

Previous interventions: As shown in Table A2, Three (37.5\%) of the schools received water supply interventions from 2010 - 2015. Two of these interventions included the installation of rain water harvesting system, one of which has never been operational due to faulty construction and missing parts. The third intervention included provision of water tanks for teacher hous- 
ing. While no drinking water interventions occurred in the past 5 years, most schools reported receiving clay water filters prior to 2010. These interventions were unsuccessful as insufficient filters were provided to treat enough water for all students. Additionally, it was unsustainable due to the fact that these filters have since broken and no replacement parts were locally available.

Table A2: Direct donor and government activities for school WaSH interventions in Trapeang Chour Commune (responses for 2010 - 2015) $(\mathrm{n}=8)$.

\begin{tabular}{|c|c|c|}
\hline Intervention & $\begin{array}{l}\text { Percent } \\
\text { schools }\end{array}$ & Interventions 2010-2015 \\
\hline Water supply & $37.5 \%$ & $\begin{array}{l}\text {-School } 8 \text { was provided with water } \\
\text { storage tanks for the teacher living } \\
\text { area. } \\
\text {-School } 2 \& 6 \text { were provided with con- } \\
\text { crete rainwater collection tubes }\end{array}$ \\
\hline $\begin{array}{l}\text { Drinking water } \\
\text { treatment }\end{array}$ & $0 \%$ & \\
\hline $\begin{array}{l}\text { Latrines and } \\
\text { sanitation }\end{array}$ & $37.5 \%$ & $\begin{array}{l}\text {-School } 6 \text { received education on proper } \\
\text { latrine use } \\
\text { - School } 1 \& 2 \text { received latrine structur- } \\
\text { al support and/or improvement }\end{array}$ \\
\hline Hand washing & $37.5 \%$ & $\begin{array}{l}\text {-School } 2,3 \text { \& } 6 \text { received education on } \\
\text { hand washing } \\
\text {-School } 2 \text { was provided with hand } \\
\text { washing resources (i.e. soap, clothes, } \\
\text { basins, etc.) }\end{array}$ \\
\hline
\end{tabular}

Table A3: WaSH related resources and facilities in the Trapeang Chour Commune, Cambodia.

\begin{tabular}{|c|c|}
\hline Facilities/Resources & $\%$ schools $(n=8)$ \\
\hline \multicolumn{2}{|c|}{$\begin{array}{l}\text { Primary Water Source in the Dry Season (multiple responses al- } \\
\text { lowed) }\end{array}$} \\
\hline Tube Well & $75.0 \%(6)$ \\
\hline Purchase from outside & $37.5 \%(3)$ \\
\hline Surface Water & $37.5 \%(3)$ \\
\hline \multicolumn{2}{|c|}{$\begin{array}{l}\text { Primary Water Source in the Wet Season (multiple responses al- } \\
\text { lowed) }\end{array}$} \\
\hline Surface water & $50.0 \%(4)$ \\
\hline Stored Rainwater & $25.0 \%(2)$ \\
\hline Purchase from outside & $37.5 \%(3)$ \\
\hline Tube Well & $37.5 \%(3)$ \\
\hline Water source at time of survey & $87.5 \%(7)$ \\
\hline Functioning Tube Well & $75.0 \%(6)$ \\
\hline Tube well produces enough water year round & $37.5 \%(3)$ \\
\hline Treated drinking water & $0.0 \%(0)$ \\
\hline Functional latrine(s) & $87.5 \%(7)$ \\
\hline Water in functioning latrines & $75.0 \%(6)$ \\
\hline Hand washing area & $50.0 \%(4)$ \\
\hline Water at hand washing area & $37.5 \%(3)$ \\
\hline Soap at hand washing area & $12.5 \%(1)$ \\
\hline
\end{tabular}

Current situation: In the dry season, the most commonly reported water source was a tube well $(75 \%)$. As shown in Table A3, only $37.5 \%$ of the schools reported sufficient water production from a tube well for latrine use, cleaning of latrines, hand washing, and drinking water. In the wet season, primary water sources varied, including surface water $(50 \%)$, tube well $(37.5 \%)$, purchased from an outside source $(37.5 \%)$, and stored rainwater $(25 \%)$. Of the eight schools, $12.5 \%$ reported a broken tube well and $25 \%$ reported a non-functional rainwater harvesting system. The only school that did not have a water source at time of observation was built with an inoperable rainwater harvesting and a tube well was not possible due to insufficient water tables. Faulty construction plays a considerable role in lack of substantial school water supply in the Trapeang Chour region.

No schools provided treated drinking water to students. However, all schools did instruct students to bring clean water from home or to buy clean water from the market. It was reported common for students to bring drinking water to school $(87.5 \%)$. Respondents were asked whether they thought children brought enough drinking water for the whole day and if they thought water brought from home was safe. Based on responses, only $25 \%$ of participants thought students had enough drinking water to last throughout the school day and $50 \%$ of participants were either unsure $(12.5 \%)$ about water quality or felt the water brought from home was unsafe $(37.5 \%)$. Among the schools with a water source $(\mathrm{n}=7)$, as shown in Figure A1a, based on E. coli counts; $57 \%$ of schools' water sources could be classified as safe; $28.5 \%$ of schools' water sources had $E$. coli counts that were considered to have possibly unsafe water; $14.3 \%$ of schools' water source had $E$. coli counts that classified the water as very high risk/unsafe. Figure A1b pictures examples for each of these categories.

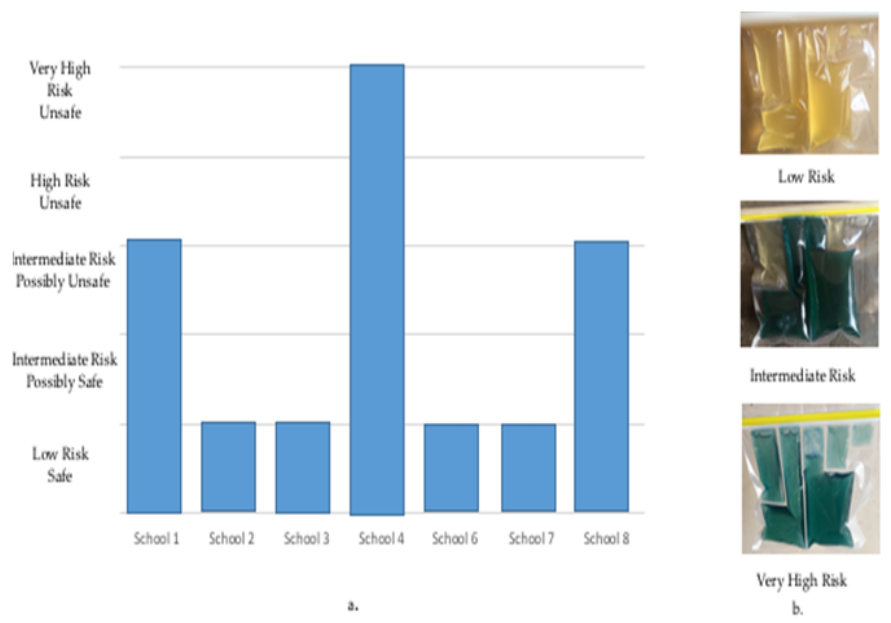

Figure A1: Drinking water safety based on E.Coli counts utilizing the rapid Aquagenex test kit from the Trapeang Chour Commune, Cambodia.

${ }^{a}$ All water sample locations were determined by the reported main source of water in march 2016. School 5 had no water source. Water safety from 7 schools in Trapeang Chour were classified based on E.Coli counts from the Aquagenex rapid field test. Schools 1,2,3,6,7,8 water samples came from a tube well on premise. School 4 water sample came from the Aoral River.

${ }^{b}$ Example of water samples classified as low risk, intermediate risk, and very high Risk.

\section{Sanitation facilities}

Previous interventions: Three of the eight schools (37.5\%) received direct donor and/or government interventions for sanitation projects between 2010 - 2015 (Table A2). Of these three, two interventions focused on structural support and one focused 
on educational activities.

Current situation: In the study area, $100 \%$ of schools had improved sanitation facilities on premise. All of these facilities were pour-flush latrines. Six schools (75\%) reported gender-segregated sanitation facilities. Seven schools $(87.5 \%)$ reported utilization of at least one latrine. The school that reported disuse of all sanitation facilities was because the school had no water source. Five schools (62.5\%) reported disuse of at least one, if not multiple, latrine(s). Among these schools there were 8 unused latrines. Figure A2 depicts reported reasons for sanitation facility disuse, including; broken latrine base (37.5\%), broken door $(12.5 \%)$, no water $(25 \%)$, and inconvenient location $(25 \%)$. Upon observation, the total number of functional latrines was 23. Doors were non-functional on $30 \%$ of the latrines, suggesting a higher rate of latrine disuse as well as a higher rate of gender-desegregated latrines than originally reported.

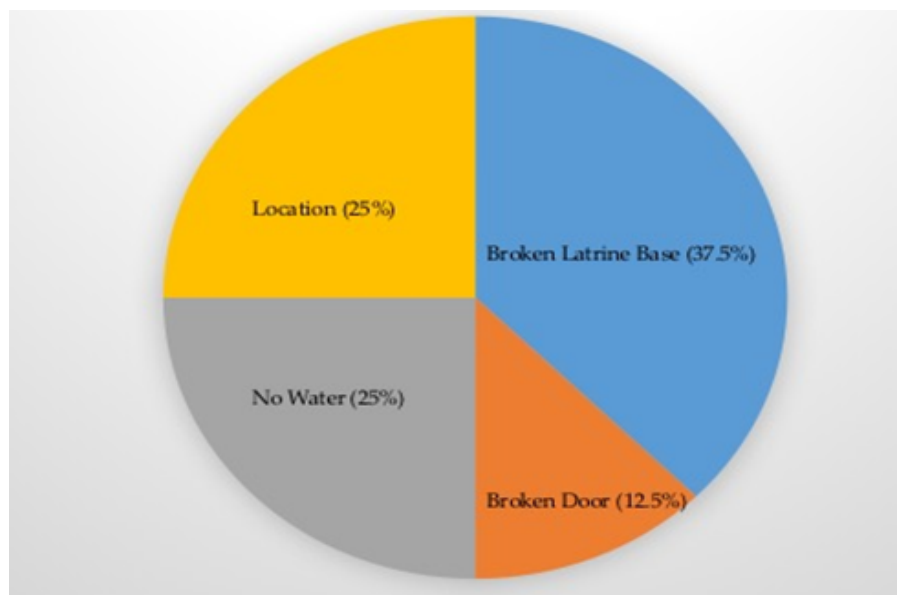

Figure A2: Reported reasons for latrine disuse in the Trapeang Chour Commune, Cambodia ( $\mathrm{n}=8$ latrines)

Cleaning of sanitation facilities ranged from two times per day $(12.5 \%)$ to one time per week $(12.5 \%)$, with the most common response of one time per day (37.5\%). All schools with functioning latrines $(n=7)$ reported that students or student groups were responsible for cleaning and basic daily maintenance of sanitation facilities. At the time of observation, school latrines had a noticeable smell at four of the schools (57\%) and feces were present in at least one latrine at two schools $(28.6 \%)$. Presence of a smell in latrines indicates lack of proper cleaning or maintenance. Latrine cleanliness has been reported as an important factor for latrine utilization (School Facilities Assessment, 2009).

Most student to latrine ratios were much higher than ideal (i.e. they never met the ideal). Student to larine ratio is based on the number latrines present (utilized and non-utilized). Whereas the student to functioning latrine ratio is based on how many latrines were reported to be utilized at time of the survey. The majority of published literature only reports student to latrine ratios, however, it is imperative to consider the number of functional latrines as this is more indicative of student latrine access and utilization. The median student to latrine ratio was 108 students and the median student to functioning latrine was 137 students (Table A1). UNICEF's guideline for student to latrine ratio is 50:1 for boys and 25:1 for girls (Shantz, et al. 2014). Thus, both of the calculated medians and the school's entire stu- dents to functioning latrine ratios did not meet UNICEF'S standard.

\section{Hand washing and hygiene}

Previous interventions: Three schools $(37.5 \%)$ received interventions focused on hand washing between 2010 - 2015 (Table A2). Two $(66.7 \%, n=3)$ of these interventions focused on hand washing education, including the optimal times to wash hands and the steps to correctly washing hands. One $(33.3 \%, n=3)$ intervention included provision of resources, including hand washing basins, hand soap, and a cloth for drying hands.

Current situation: Four of the eight schools $(50 \%, \mathrm{n}=8)$ had a designated hand washing area with $12.5 \%$ schools that had a hand washing station on the path from the latrines to the classrooms. Three schools (37.5\%) provided water at the hand washing area at time of observation. These hand washing areas included two types of hand washing stations; 1) Two basins: one basin with clean water and a cup to scoop the water over hands and one basin to catch the dirty water (12.5\%). 2) Concrete rainwater collection structure(s) with tap(s) to turn the water on and off $(37.5 \%)$. One concrete hand washing station was non-functional due to faulty construction. Even though $100 \%$ of the schools' report buying soap for hand washing in the past year, only $12.5 \%$ of schools provided soap to students at the time of observation. Similarly, four schools $(50 \%)$ reported buying basins for hand washing with only one school that made the basins available for student use, showing a clear disconnect between reported $\mathrm{WaSH}$ purchases and resource allocation.

\section{SWaSH management}

Accountability and responsibilities: For the accountability and responsibilities section, only the schools with a water source at the time of the SWaSH assessment were considered $(n=7)$. All schools with a water source reported having a system to remind people whose job it was to collect water and $85.7 \%(n=6)$ of these schools' reported having a duty roster visible. Upon observation and after asking key informants where duty rosters were located, only one school (14.3\%) had a duty roster on display for water collection and two schools $(28.6 \%)$ had a duty roster on display for the cleaning of latrines. At the majority of schools $(85.7 \%)$, school directors were responsible for ensuring soap was provided to children for hand washing. Five schools reported reminding students to wash hands (71.4\%). Of these five, teachers were responsible for instructing students to wash their hands at four of the schools.

All schools in the Trapeang Chour Commune had a School Support Committee (SSC) and/or Parent Teacher Association (PTA). Only one (12.5\%) of these groups was involved in hygiene education and no support of daily SWaSH management or resources was provided by the SSC and/or PTA at any of the schools. Respondents at $75 \%$ of the schools reported that teachers have responsibilities regarding SWaSH. When asked what teachers' responsibilities were, responses included:

- Remind students to: complete school chores (37.5\%), bring clean water from home $(37.5 \%)$, put water in the latrines $(25 \%)$, clean the school (12.5\%), and wash their hands (12.5\%)

- Check if there is water in the latrine $(12.5 \%)$

- Be a good example for students by demonstrating correct WaSH behavior (25\%)

- Teach lessons on hygiene (12.5\%) 
Supply chain for SWaSH resources: One (12.5\%) school reported that replacement soap was not purchased locally and four schools (50\%) reported that cleaning supplies (e.g. brooms, mops, cleaning rags, etc.) were not purchased locally. Three of the four schools that reported not buying cleaning supplies locally reported that cleaning supplies were too expensive if purchased locally and one reported that cleaning supplies were not available locally. Only three schools (37.5\%) had cleaning supplies in stock at the time of the survey.

General WaSH perceptions: No stakeholders were satisfied with the latrine and sanitation situation in their respective schools with $62.5 \%$ expressing plans to improve latrines and sanitation within the next few years. All schools expressed plans to improve water supply, five schools $(62.5 \%)$ planned to improve drinking water and seven $(87.5 \%)$ schools planned to improve hand washing. While all key informants expressed desire to improve at least one aspect of SWaSH, all key informants also answered 'true' to the statement, "Cannot spend additional time and attention [on water supply, drinking water, and sanitation] because there are not enough financial resources". This discrepancy demonstrates that while stakeholders may have had good intentions to improve $\mathrm{SWaSH}$, the reality is that improvementsmay not have been possible due to lack of financial resources inhibiting their ability to not only build infrastructure but also maintain current infrastructure and purchase consumable goods, posing a serious problem for sustainability and meriting innovative solutions.

Lastly, it is important to note that all key informants expressed childhood diarrheal disease as a concern in the community and stated that diarrhea could be prevented by drinking clean or boiled water with $37.5 \%$ mentioning that utilizing latrines could contribute to diarrheal prevention. This was an important finding as researchers were unaware to what extent diarrheal disease affected school children in this region or if key stakeholders knew WaSH related methods for diarrheal prevention.

\section{Discussion}

\section{SWaSH Monitoring and Management}

This assessment aimed to gather baseline $\mathrm{SWaSH}$ data, as there was a lack of systematic, standardized, and consistent $\mathrm{SWaSH}$ data reported to the regional and/or national government. Some key informants expressed reporting $\mathrm{SWaSH}$ information to the Provincial Department or the Office of Education, Youth, and Sport, however no reports could be located regarding the $\mathrm{SWaSH}$ situation in the Trapeang Chour Commune. Inconsistencies existed in the way respondents interpreted questions regarding $\mathrm{SWaSH}$ financial expenses and allocation of SWaSH resources, therefore, researchers did not report any of this data. Thus, it is recommended that simple indicators be developed and utilized for consistent monitoring of SWaSH situations. Such a system has the potential to enhance the quality of $\mathrm{SWaSH}$ conditions, ensure schools in a variety of regions receive equal attention, and assist with the provision of timely facility repairs.

The majority of teachers' responsibilities regarding SWaSH were to remind students to complete tasks with the bulk of daily responsibilities falling on students. In several settings, school chores are a successful mechanism for ensuring water is present in latrines, at hand washing stations, and at drinking water locations and for maintaining the cleanliness of latrines and school grounds (Field Guide: UNICEF, 2013). However, students were unable to manage repairs or replace resources. This show a clear disconnect between assumed responsibility and actual power to make changes or sustain SWaSH efforts. Lack of school director, teacher and/or community involvement can contribute to the inability to properly maintain $\mathrm{SWaSH}$ facilities and lack of resources allocation. A system must be introduced to ensure timely facility repairs and replacement of resources, such as soap and cleaning supplies.

\section{Failed interventions}

A clear disparity exists between regional SWaSH efforts in rural Cambodia. Many organizations focus on WaSH in challenging environments or provinces with low annual GDP. Little to no attention is allocated to rural and agricultural areas that may struggle to obtain a consistent year round water source; regions similar to the target area explored in this study. Kampong Speu Province has a higher GDP than that of other provinces, however, this GDP comes mainly from the provincial town, whereas rural areas have much less wealth than the provincial town and many community members are subsistent farmers with little means to earn additional income (Planning NIoSMo, 2013).

Even when interventions have been attempted in these eight governmental schools, they have often been unsuccessful. Several factors contributed to these intervention failures, most notably lack of; 1) Coordinated efforts 2) Sustainable water source 3) Construction oversight 4) Availability and affordability of replacement resources (e.g. soap, cleaning supplies, pipes and taps for hand washing stations) and 5) Participation from school directors, teachers and community members. Interestingly, three schools had received intervention(s) on water supply, latrines and sanitation, and/or hand washing between 2010 - 2015. However, interventions occurred at 3 different schools from two separate organizations, indicating a lack of coordinated efforts. A greater potential impact is possible with organization coordination and communication. A holistic approach has not been taken to $\mathrm{SWaSH}$ in this area, with organizations often neglecting to consider key factors. For example, neglecting to acknowledge the lack of sustainable year round water source prior to conducting intervention(s) on hand washing or latrines/sanitation will lead to intervention failure. Although infrastructure improvement has been attempted at some schools, disappointedly, faulty construction and lack of construction oversight has contributed to the presence of non-functioning, but extremely important infrastructure (e.g. rainwater harvesting systems, hand washing stations). Lastly, SWaSH interventions must be welcomed by school directors, teachers, and community members. These interventions are often more successful when schools are required to provide initial monetary or capital resources. Even when directors and teacher "buy-in" to an intervention they may lack the ability to sustain efforts due to financial and/or time constraints or lack of know-how. In this case, it is extremely important to engage community members to ensure replacement resources and repairs. Previous failures must be both acknowledged and considered in the implementation of future SWaSH interventions. 


\section{Future directions and recommendations}

SWaSH Guidelines and Safety: The majority of schools in this study did not meet the minimum school water, sanitation, and hygiene ( $\mathrm{SWaSH})$ guidelines published by UNICEF. These guidelines can be found in the Three Star Approach for WaSH in Schools, which categorize SWaSH achievements from "no stars" to "three stars" (Field Guide: UNICEF, 2013). To attain even the first star, the school must have daily supervised group hand wash, daily supervised cleaning of toilets with provision of soap and water in each latrine, at least one functional toilet for girls and one toilet for boys, and daily supervised use of drinking-water bottles by all children. Only one school had soap present at the time of observation, however, this school still did not meet all requirements to attain one star as no drinking water was provided to students and it was uncommon for students to bring drinking water from home. Thus, no schools in Trapeang Chour could receive any stars according to these guidelines. Since no schools provided treated drinking water, researchers observed students drinking directly from untreated water sources, some of which were positive for E. coli. Implementing culturally adapted guidelines in all eight schools is the first step to ensuring equitable access to SWaSH among all students and has the potential to decrease absenteeism and improve overall health outcomes (McMahon, et al., 2011; Freeman, et al., 2012; Saboori, et al., 2013).

Menstrual hygiene management: The $\mathrm{WaSH}$ sector has not widely addressed menstrual hygiene management (MHM), however, more emphasis must be placed on their role in creating girl-friendly schools (Mahon, et al., 2010; House, et al., 2012). Improving gender equity, particularly through $\mathrm{SWaSH}$, will demand an integrated approach. Ability to access both $\mathrm{SWaSH}$ infrastructure and education on MHM is essential in this integration. Infrastructure such as; gender segregated toilets, locking doors, clean water and wastebaskets in latrines has been shown to decrease female absenteeism (Birdthistle, et al., 2011). Additionally, as shown in a study from Tanzania, decreased female absenteeism resulted from puberty education utilizing the "Growth and changes" book (Sommer, M, 2011). This book has been adapted for Cambodia and approved by the Ministry of Education (Sommer, M, 2012). While MHM was not specifically evaluated in this study, it was observed that several latrine doors did not lock and only one school had latrines with gender segregated toilet blocks. There is significant importance in addressing MHM in future SWaSH interventions.

Sustainability: The sustainability of school water, sanitation, and hygiene ( $\mathrm{SWaSH})$, particularly in rural areas of developing countries, continues to be a challenge (Saboori, et al., 2011). Thus, there is an immense need for continuous support and continued stakeholder engagement. Sustainable Schools International (SSI) has worked in the eight government schools in this rural commune for over ten years and is committed to continuing service. One way SSI demonstrates commitment is by training local leaders to address community needs. The researchers recommended engaging local organizations, such as SSI, when moving forward with SWaSH development, implementation, monitoring and evaluation in this region. Additionally, engaging school directors and teachers by utilizing a community-capacity framework to identify the unique strengths of this population will be a powerful tool for substantiality.
Study limitations: This research could have benefited from previous rapport building with school directors, such that respondents would have felt more comfortable to expose sensitive information that might be inconsistent with the Ministry of Education's (MoE) standards. Onsite translation, between Khmer and English, was time consuming and contributed to surveyor fatigue and inability for two respondents to complete the entire questionnaire. Additionally, the language barrier served as a limitation as not all terms or phrases had direct translations.

Despite the limitations, this study was important to Trapeang Chour as the first baseline SWaSH assessment in this region. The study fills knowledge gaps on $\mathrm{SWaSH}$ in this region, contributing baseline data for future development of sustainable SWaSH interventions.

\section{Conclusions}

The lack of regionally implemented and sustained WaSH solutions has led to poor SWaSH conditions in Cambodia and other developing countries. This study provides needed SWaSH baseline data in the eight schools of Trapeang Chour demonstrating lack of SWaSH access and sustainability. To ensure equitable SWaSH access, there is a need for locally accepted, coordinated, evidence-informed and sustainable interventions. Additionally, consistent SWASH reporting indicators and consideration of menstrual hygiene management merit environmental and public health research.

Supplementary Materials: The UNICEF 3 star approach for WaSH in Schools can be found at: http://www.unicef.org/wash/ schools/files/UNICEF_Field_Guide-3_Star-Guide.pdf. Additionally, a copy of our key informant interview survey was attached as a supplementary file.

Acknowledgments: The Colorado School of Public Health, the Department of Environmental and Radiological Health at Colorado State University, and Sustainable Schools International (Fort Collins, CO) provided funding support for this project. The authors would like to thank Kong Sem for his support in contacting respondents and providing transportation, Ray Cantwell with Samaritan's purse and Clear Cambodia for providing the WaSH questionnaires and observational surveys, Sam Tan for interpreting support, and Trapeang Chour school respondents for taking the time to participate in this study.

Author Contributions: TaviaMirassou-Wolf and Ven Chanthou conducted the school WaSH questionnaires, observational surveys, and Aquagenx E. coli rapid tests. Tavia Mirassou-Wolf imputed and analyzed all data. Tavia Mirassou-Wolf and Dr. Elizabeth P. Ryan wrote the first draft of the manuscript. Maureen DeCoursey and Kari Grady-Grossman provided support in the recruiting and contacting of respondents. All authors contributed to the revising of the manuscript; all authors read and approved the final manuscript.

Conflicts of Interest: The authors declare no conflict of interest. 


\section{Reference}

1. Birdthistle, I., Kelly, D., Freeman, M., et al. What impact does the provision of separate toilets for girls at school have on their primary and secondary school enrolment, attendance and completion? A systematic review of the evidence. (2011) EPPI-Centre, Social Science Research Unit, Institute of Education, University of London.

Pubmed $\mid$ Crossref $\mid$ Others

2. Centre JSBaS. Economic Census of Cambodia 2011. (2013) Cambodian National Institute of Statistics.

Pubmed $\mid$ Crossref $\mid$ Others

3. Field Guide: The Three Star approach for WaSH in Schools. (2013)

UNICEF, GIZ.

Pubmed | Crossref $\mid$ Others

4. Freeman, M.C., Porter, S., Rheingans, R. Assessing the sustainability \& effectiveness of school WASH projects: a tool kit. (2010) Center for Global Safe Water at Emory University, USA.

Pubmed $\mid$ Crossref $\mid$ Others

5. Freeman, M.C., Greene, L.E., Dreibelbis, R., et al. Assessing the impact of a school-based water treatment, hygiene and sanitation programme on pupil absence in Nyanza Province, Kenya: a cluster-randomized trial. (2012) Trop Med Int Health 17(3): 380-391.

Pubmed $\mid$ Crossref $\mid$ Others

6. Greene, L.E., Freeman, M.C., Akoko, D., et al. Impact of a schoolbased hygiene promotion and sanitation intervention on pupil hand contamination in Western Kenya: a cluster randomized trial. (2012) Am J Trop Med Hyg 87(3): 385-393.

Pubmed | Crossref | Others

7. House, S., Mahon, T., Cavill, S. Menstrual hygiene matters: a resource for improving menstrual hygiene around the world. (2012) London, England: WaterAid.

Pubmed $\mid$ Crossref $\mid$ Others

8. Hunter, P.R., Risebro, H., Yen, M., et al. Impact of the provision of safe drinking water on school absence rates in Cambodia: a quasi-experimental study. (2014) PLoS One 9(3): e91847.

Pubmed | Crossref | Others

9. ISF-UTS. Cambodia Water, Sanitation and Hygiene Sector Brief. (2011) AusAID, The institute for Sustainable Futures, University of Technology.

Pubmed $\mid$ Crossref $\mid$ Others

10. Jasper, C., Le, T.T., Bartram, J. Water and sanitation in schools: a systematic review of the health and educational outcomes. (2012) Int J Environ Res Public Health 9(8): 2772-2787.

Pubmed | Crossref | Others

11. Jordanova, T., Cronk, R., Obando, W., et al. Water, sanitation, and hygiene in schools in low socio-economic regions in Nicaragua: a cross-sectional survey. (2015) Int J Environ Res Public Health 12(6): 6197-6217.

Pubmed | Crossref | Others

12. Mara, D., Lane, J., Scott, B., et al. Sanitation and health. (2010) PLoS Med 7(11): e1000363.

Pubmed | Crossref | Others

13. Mahon, T., Fernandes, M. Menstrual hygiene in South Asia: A neglected issue for WASH (water, sanitation and hygiene) programmers. (2010) Gender \& Development 18(1): 99-113. 5.

Pubmed | Crossref | Others
14. Mbuya, M.N., Humphrey, J.H. Preventing environmental enteric dysfunction through improved water, sanitation and hygiene: an opportunity for stunting reduction in developing countries. (2016) Matern Child Nutr 12(Supp11): 106-120.

Pubmed | Crossref | Others

15. McMahon, S.A., Winch, P.J., Caruso, B.A., et al. The girl with her period is the one to hang her head' Reflections on menstrual management among schoolgirls in rural Kenya. (2011) BMC Inter Health Hum Rights 16(11): 1-7.

Pubmed | Crossref | Others

16. Planning NIoSMo. Economic Census of Cambodia 2011, Provincial Report: 05 Kampong Speu Province Phnom Pehn. (2013) Cambodia.

Pubmed $\mid$ Crossref $\mid$ Others

17. Rah, J.H., Cronin, A.A., Badgaiyan, B., et al. Household sanitation and personal hygiene practices are associated with child stunting in rural India: a cross-sectional analysis of surveys. (2015) BMJ Open 5(2): e005180.

Pubmed | Crossref | Others

18. Saboori, S., Mwaki, A., Porter, S., et al. Sustaining school hand washing and water treatment programs: Lessons learned and to be learned. (2011) Waterlines 30(4): 289-311.

Pubmed | Crossref | Others

19. Saboori, S., Greene, L.E., Moe, C.L., et al. Impact of regular soap provision to primary schools on hand washing and E. coli hand contamination among pupils in Nyanza Province, Kenya: a cluster-randomized trial. (2013) Am J Trop Med Hyg 89(4): 698-708.

Pubmed | Crossref | Others

20. School Facilities Assessment: Baseline to End of Uear 2 Comparisons. (2009) Emory University Center for Global Safe Water.

Pubmed $\mid$ Crossref $\mid$ Others

21. Shantz, A., Ham, O., MacLeod, M., et al. WaSH in rural Cambodian primary schools: roles, responsibilities, attitudes and priorities of key stakeholders. (2014) 37th WEDC International Conference; Hanoi, Vietnam p: 6.

Pubmed $\mid$ Crossref $\mid$ Others

22. Sommer, M. An Early Window of Opportunity for Promoting Girls' Health: Policy Implications of the Girl's Puberty Book Project in Tanzania. (2011) Global J Health Edu Promotion 2011(14): 77-92.

Pubmed $\mid$ Crossref $\mid$ Others

23. Sommer, M., Connolly, Susan. Growth and Changes 2012.

Pubmed $\mid$ Crossref $\mid$ Others

24. Spears, D., Ghosh, A., Cumming, O. Open defecation and childhood stunting in India: an ecological analysis of new data from 112 districts. (2013) PLoS One 8(9): e73784.

Pubmed | Crossref | Others

25. Trapeang Chour Census data 2008. (2016).

Pubmed $\mid$ Crossref $\mid$ Others

26. UNICEF W. Progress on Drinking Water and Sanitation 2014 update. (2014) Switzerland World Health Organization \& UNICEF.

Pubmed $\mid$ Crossref $\mid$ Others

27. UNICEF. The State of the World's Children 2015: Country Statistical Information. (2015) UNICEF.

Pubmed $\mid$ Crossref $\mid$ Others

28. WHO. Diarrhoeal Disease: Factsheet N 330 (2013) World Health

Organization.

Pubmed $\mid$ Crossref $\mid$ Others
Ommega Online Publishers

Journal Title: Journal of Environment and Health Science (JEHS)

Journal Short Name: J Environ Health Sci
Journal ISSN: 2378-6841

E-mail: environmentalscience@ommegaonline.org

Website: www.ommegaonline.org 